\title{
Precipitation Parameters of Stochastic Climate Models for a Changing Climate
}

B.N. Wilson ${ }^{1}$, A.Y. Sheshukov ${ }^{2}$

ISELE Paper Number 11080

Presented at the

\section{International Symposium on Erosion and Landscape Evolution}

\author{
Hilton Anchorage Hotel, Anchorage, Alaska
}

September 18-21, 2011

\begin{abstract}
A Specialty Conference of the
American Society of Agricultural and Biological Engineers

Held in conjunction with the Annual Meeting of the Association of Environmental \& Engineering Geologists
\end{abstract}

September 19-24, 2011

\footnotetext{
${ }^{1}$ Bruce N. Wilson, Professor, Department of Bioproducts and Biosystems Engineering, University of Minnesota, 1St. Paul, Minnesota 55108, USA. (Phone (612) 625-6770, Email: wilson@umn.edu).

${ }^{2}$ Aleksey Y. Sheshukov, Research Associate, Department of Biological and Agricultural Engineering, Kansas State University, Manhattan, Kansas 66506-2906, USA. (Phone (785) 532-5418, Email: ashesh@ksu.edu)
} 


\title{
Precipitation Parameters of Stochastic Climate Models for a Changing Climate
}

\author{
B.N. Wilson ${ }^{1}$, A.Y. Sheshukov ${ }^{2}$
}

\begin{abstract}
Changing climate can impact erosion directly by increasing or decreasing the rainfall depth and intensity and indirectly by influencing the vegetative cover on landscapes. Stochastic climate models are increasingly being used to allow the assessment of erosion to be done using ensemble statistics. Precipitation is mostly widely represented by first determining the state of the day is wet or dry using discrete transitional probabilities and then, for a wet day, determining the precipitation depth. The parameters for stochastic models are based on the statistical analysis of observed data for the current conditions. Simple methods to modify these stochastic parameters under different climate scenarios are desired to easily simulate their impact on erosion. Modifying parameters for precipitation depth needs to be considered carefully because changes in depth can be achieved by varying the statistics of daily precipitation, by changing the number of wet days, or by a combination of these statistics. A framework for modifying the precipitation depth for new climate conditions is developed in the study. In addition to the stochastic climate parameters related to the moments of probability density functions and transitional probabilities under the current conditions, the proposed framework requires the user to specify the fractional changes in the total precipitation depth and the mean daily precipitation depth. Relationships are developed to determine indirectly the proper number of wet days from transitional probabilities for a first-order Markov chain. These relationships are dependent on a user-specified parameter of the ratio of the mean number of wet-wet day sequences of the current and new climate conditions. The sequence of wet-wet days is important in modeling soil erosion. The framework is applied to 80 years of precipitation data for Stillwater, OK. The implications of assuming no change in the wet-wet-day ratio with new climate conditions is compared to the results obtained assuming a ratio equal to the fractional change in the mean number of wet days. If the new climate condition corresponds to an increase in the number of wet days, the assumption of an unchanged ration corresponds to new storm patterns that develop more often on dry days and dissipate more rapidly on wet days. The opposite trend occurs if the new climate condition corresponds to a decrease in the number of dry day. Under this scenario, storm patterns tend to dissipate more slowly resulting, on average, in more frequent consecutive days with precipitation. A wet-wet day ratio equal to the fractional change in the mean number of wet days corresponds to no change between the current and new climate conditions of the transitional probability of wet-given- wet-day. This result suggests that the persistence of storm systems do not change under the new climate conditions. The proposed framework is useful and easy to implement in stochastic climate models.
\end{abstract}

KEYWORDS. Erosion, Stochastic model, Precipitation, Climate change.

\footnotetext{
${ }^{1}$ Bruce N. Wilson, Professor, Department of Bioproducts and Biosystems Engineering, University of Minnesota, 1St. Paul, Minnesota 55108, USA. (Phone (612) 625-6770, Email: wilson@umn.edu).

${ }^{2}$ Aleksey Y. Sheshukov, Research Associate, Department of Biological and Agricultural Engineering, Kansas State University, Manhattan, Kansas 66506-2906, USA. (Phone (785) 532-5418, Email: ashesh@ksu.edu)
} 


\section{INTRODUCTION}

Climate change can significantly impact erosion processes. These impacts include direct changes in the erosivity of rainfall by increasing or decreasing the precipitation depths and rainfall intensities. Possible indirect impacts include changes in the vegetative cover on the landscape, in soil erodibility with freeze-thaw cycling, and in biological activities that influence infiltration and subsequent surface flow rates. Since soil erosion is a process of fundamental importance, it should be included in the studies that examine potential impacts of climate change.

Stochastic climate models are useful tools to assess the impact of natural variability in weather conditions on soil erosion. Examples of climate models used for erosion studies include CLIGEN (Richardson, 1981; Nicks et al., 1995) and WINDS models (Wilson et al., 2006; Wilson and Sheshukov, 2006). These models use observed weather data, under current conditions, to compute the necessary ensemble statistics. Care is needed to convert these ensemble weather statistics to appropriate values for a changing climate. This is particularly important in the estimates of precipitation. Precipitation depth in stochastic models is usually determined by first determining if the state of day is wet or dry using discrete transitional probabilities and then, for a wet day, determining the precipitation depth. Stochastic climate models can therefore achieve a new precipitation depth for a month (or some other time period) by varying the ensemble statistics related to daily precipitation depth or by changing the number of wet days.

The objective of this paper is to derive and discuss basic relationships for computing precipitation depth for a changing climate. Methods are presented for determining new precipitation depths from current ensemble statistics and key input parameters using a different number of wet days, using new daily mean depth, or using a combination of these two factors. The relationships are applied to previous published precipitation parameters for the month of April for Stillwater, OK.

\section{GENERAL FRAMEWORK}

The proposed framework allows for changes in precipitation depth by varying the number of wet days and by changing the statistics of daily depth. The average precipitation depth for a convenient (say, monthly) time period over $m$ years is formally defined as

$$
E\left(P_{T}\right)=\frac{\sum_{i=1}^{m} \sum_{j=1}^{n_{i}} r_{i, j}}{m}=\frac{\sum_{i=1}^{m} n_{i} \bar{r}_{i}}{m}=E(r) \frac{\sum_{i=1}^{m} n_{i}}{m}=E(r) E\left(n_{w}\right)
$$

where $r_{i, j}$ is the precipitation depth for the jth event in the ith year, $\bar{r}_{i}$ is the average depth per event for the ith year, and $n_{i}$ is the number of precipitation events. By using the same mean statistic for all years, the sample estimate of the average precipitation depth can be replaced by the ensemble population value (i.e., $E(r))$. $E\left(n_{w}\right)$ is the population average number of wet days during the time period of interest.

Let's consider a change in the $\mathrm{E}\left(\mathrm{P}_{\mathrm{T}}\right)$ because of changes in climate. The subscript "o" will be used for statistics computed from current conditions and subscript " $n$ " for the new climate conditions. The ratio of new and current mean precipitation depth is represented by a multiplicative adjustment factor of $\lambda_{\mathrm{T}}$ defined as 


$$
\lambda_{\mathrm{T}}=\frac{\mathrm{E}\left(\mathrm{P}_{\mathrm{Tn}}\right)}{\mathrm{E}\left(\mathrm{P}_{\mathrm{To}}\right)}=\frac{\mathrm{E}\left(\mathrm{n}_{\mathrm{w}, \mathrm{n}}\right) \mathrm{E}\left(\mathrm{r}_{\mathrm{n}}\right)}{\mathrm{E}\left(\mathrm{n}_{\mathrm{w}, \mathrm{o}}\right) \mathrm{E}\left(\mathrm{r}_{\mathrm{o}}\right)}
$$

where the relationship of Eq. 1 has been used. A framework for dividing the total change into separate components for changes in the mean daily depth and in the number of wet days can be obtained by using ratios of

$$
\lambda_{r}=\frac{E\left(r_{n}\right)}{E\left(r_{o}\right)} \quad \text { and } \quad \lambda_{w}=\frac{E\left(n_{w, n}\right)}{E\left(n_{w, o}\right)}
$$

where $\lambda_{\mathrm{r}}$ and $\lambda_{\mathrm{w}}$ are the ratios between new and current daily mean depths and mean numbers of wet days, respectively. By combining equations, we conclude that

$$
\lambda_{\mathrm{w}}=\frac{\lambda_{\mathrm{T}}}{\lambda_{\mathrm{r}}}
$$

New climate conditions can be reported using fractional changes of current values. By using the fractional change in total precipitation depth $\left(\mathrm{f}_{\mathrm{T}}\right)$ defined as

$$
\mathrm{f}_{\mathrm{T}}=\frac{\mathrm{E}\left(\mathrm{P}_{\mathrm{Tn}}\right)-\mathrm{E}\left(\mathrm{P}_{\mathrm{To}}\right)}{\mathrm{E}\left(\mathrm{P}_{\mathrm{To}}\right)}=\lambda_{\mathrm{T}}-1
$$

and the fractional change in mean daily precipitation depth $\left(f_{\mathrm{r}}\right)$ as

$$
f_{r}=\frac{E\left(r_{n}\right)-E\left(r_{o}\right)}{E\left(r_{o}\right)}=\lambda_{r}-1
$$

the ratio of the average number of wet days can then be alternatively defined as

$$
\lambda_{\mathrm{w}}=\frac{1+\mathrm{f}_{\mathrm{T}}}{1+\mathrm{f}_{\mathrm{r}}}
$$

For our proposed solution approach, the user needs to specify the input parameters of $f_{T}$ and $f_{r}$. By using Eq. $4 \mathrm{a}$ to compute $\lambda_{\mathrm{w}}$, the required mean number of wet days is then defined as

$$
\mathrm{E}\left(\mathrm{n}_{\mathrm{w}, \mathrm{n}}\right)=\lambda_{\mathrm{w}} \mathrm{E}\left(\mathrm{n}_{\mathrm{w}, \mathrm{o}}\right)
$$

Mean daily precipitation is an input parameter in most stochastic climate models, and therefore an adjustment in the mean daily depth using Eq. $2 \mathrm{~b}$ is relatively easy to implement. In contrast, the number of wet days is determined indirectly from transitional probabilities using a first-order Markov chain. We will therefore need to develop relationships to determine the required number of wet days given by Eq. $4 \mathrm{~b}$ from these transitional probabilities. These relationships are developed in the next section.

\section{AdJUSTMents FOR NuMber OF Wet DAYS}

In this section, relationships are developed to determine the appropriate transitional probabilities to obtain the required mean number of wet days given by Eq. $4 \mathrm{~b}$. Computational formulae typically used to compute probabilities from observed data are (Haan, 2002):

$$
P(w)=\frac{n_{w}}{N}, P(d)=\frac{n_{d}}{N} \text { and } P(d \cap d)=P(d) P(d / d)=\frac{n_{d d}}{N}
$$


and

$$
\mathrm{P}(\mathrm{w} / \mathrm{w})=\frac{\mathrm{n}_{\mathrm{ww}}}{\mathrm{n}_{\mathrm{w}}} \text { and } \mathrm{P}(\mathrm{d} / \mathrm{d})=\frac{\mathrm{n}_{\mathrm{dd}}}{\mathrm{n}_{\mathrm{d}}}
$$

where $\mathrm{P}(\mathrm{w}), \mathrm{P}(\mathrm{d}), \mathrm{P}(\mathrm{d} \cap \mathrm{d}), \mathrm{P}(\mathrm{w} / \mathrm{w})$, and $\mathrm{P}(\mathrm{d} / \mathrm{d})$ are the probabilities of a wet day, a dry day, a two-day sequence of dry-and-dry day, a wet day given that the previous day is also wet, and a dry day given that the previous day is also dry, respectively, and $\mathrm{n}_{\mathrm{w}}, \mathrm{n}_{\mathrm{d}}, \mathrm{n}_{\mathrm{wd}}$, and $\mathrm{n}_{\mathrm{dd}}$ are the numbers of wet days, dry days, sequence of wet-wet days, and sequence of dry-dry days, respectively, within the time period of interest. $\mathrm{N}$ is the total number of days within that time period.

It follows directly from their definitions that

$$
\mathrm{N}=\mathrm{n}_{\mathrm{w}}+\mathrm{n}_{\mathrm{d}}, \mathrm{n}_{\mathrm{w}}=\mathrm{n}_{\mathrm{ww}}+\mathrm{n}_{\mathrm{wd}} \text {, and } \mathrm{n}_{\mathrm{d}}=\mathrm{n}_{\mathrm{dw}}+\mathrm{n}_{\mathrm{dd}}
$$

where $n_{w d}$ and $n_{w d}$ are the number of sequence of wet-dry days and the number of sequence of dry-wet days, respectively. Because of the symmetry of counting a sequence of wet-dry days and dry-wet days, we will use $\mathrm{n}_{\mathrm{wd}}=\mathrm{n}_{\mathrm{dw}}$.

Since the total number of days is the same for the current and new climate conditions, the number of dry days for the new climate conditions,

$$
\mathrm{n}_{\mathrm{d}, \mathrm{n}}=\mathrm{N}-\mathrm{n}_{\mathrm{w}, \mathrm{n}}=\mathrm{n}_{\mathrm{w}, \mathrm{o}}+\mathrm{n}_{\mathrm{d}, \mathrm{o}}-\lambda_{\mathrm{w}} \mathrm{n}_{\mathrm{w}, \mathrm{o}}=\mathrm{n}_{\mathrm{w}, \mathrm{o}}\left(1-\lambda_{\mathrm{w}}\right)+\mathrm{n}_{\mathrm{d}, \mathrm{o}}
$$

where the number of wet days for the new climate conditions is computed by using the ratio of the means of number of wet days between the current and new climate conditions as defined by Eq. $2 \mathrm{~b}$. Since $\mathrm{n}_{\mathrm{wd}}=\mathrm{n}_{\mathrm{dw}}$, we can also conclude that

$$
\mathrm{n}_{\mathrm{wd}, \mathrm{n}}=\mathrm{n}_{\mathrm{w}, \mathrm{n}}-\mathrm{n}_{\mathrm{ww}, \mathrm{n}}=\mathrm{n}_{\mathrm{d}, \mathrm{n}}-\mathrm{n}_{\mathrm{dd}, \mathrm{n}}
$$

which limits the number of dry-dry day sequence as

$$
\mathrm{n}_{\mathrm{dd}, \mathrm{n}}=\mathrm{n}_{\mathrm{d}, \mathrm{n}}-\mathrm{n}_{\mathrm{w}, \mathrm{n}}+\mathrm{n}_{\mathrm{ww}, \mathrm{n}}
$$

To close the equation set, we will use an additional parameter, $\gamma$, which is defined as the ratio of the number of wet-wet day sequences of the current and new climate conditions. We then obtain

$$
\mathrm{n}_{\mathrm{ww}, \mathrm{n}}=\gamma \mathrm{n}_{\mathrm{ww}, \mathrm{o}}
$$

The implications of selected values for $\gamma$ are discussed in greater depth later. The number of sequence of dry-dry days for the new climate conditions can now be defined as

$$
\mathrm{n}_{\mathrm{dd}, \mathrm{n}}=\mathrm{n}_{\mathrm{d}, \mathrm{n}}-\lambda_{\mathrm{w}} \mathrm{n}_{\mathrm{w}, \mathrm{o}}+\gamma \mathrm{n}_{\mathrm{ww}, \mathrm{o}}=\mathrm{n}_{\mathrm{d}, \mathrm{n}}-\lambda_{\mathrm{w}} \mathrm{n}_{\mathrm{w}, \mathrm{o}}+\gamma\left(\mathrm{n}_{\mathrm{dd}, \mathrm{o}}+\mathrm{n}_{\mathrm{w}, \mathrm{o}}-\mathrm{n}_{\mathrm{d}, \mathrm{o}}\right)
$$

where an equivalent form of Eq. $6 \mathrm{~d}$ has been used for $\mathrm{n}_{\mathrm{ww}, \mathrm{o}}$. By using the probability relationships given by Eqs. 5a and 5b, the transitional probabilities for new climate conditions can be computed as

$$
\mathrm{P}_{\mathrm{n}}(\mathrm{w} / \mathrm{w})=\frac{\mathrm{n}_{\mathrm{ww}, \mathrm{n}}}{\mathrm{n}_{\mathrm{w}, \mathrm{n}}}=\frac{\gamma \mathrm{n}_{\mathrm{ww}, \mathrm{o}}}{\lambda_{\mathrm{w}} \mathrm{n}_{\mathrm{w}, \mathrm{o}}}=\left(\frac{\gamma}{\lambda_{\mathrm{w}}}\right) \mathrm{P}_{\mathrm{o}}(\mathrm{w} / \mathrm{w})
$$

and

$$
\mathrm{P}_{\mathrm{n}}(\mathrm{d} / \mathrm{d})=\frac{\mathrm{n}_{\mathrm{dd}, \mathrm{n}}}{\mathrm{n}_{\mathrm{d}, \mathrm{n}}}=\frac{\mathrm{n}_{\mathrm{d}, \mathrm{n}}-\lambda_{\mathrm{w}} \mathrm{n}_{\mathrm{w}, \mathrm{o}}+\gamma\left(\mathrm{n}_{\mathrm{dd}, \mathrm{o}}+\mathrm{n}_{\mathrm{w}, \mathrm{o}}-\mathrm{n}_{\mathrm{d}, \mathrm{o}}\right)}{\mathrm{n}_{\mathrm{d}, \mathrm{n}}}
$$

By using Eq. 6 b for $\mathrm{n}_{\mathrm{d}, \mathrm{n}}$ and by dividing both numerator and denominator by $\mathrm{N}$, we obtain 


$$
\mathrm{P}_{\mathrm{n}}(\mathrm{d} / \mathrm{d})=1-\frac{\lambda_{\mathrm{w}} \mathrm{n}_{\mathrm{w}, \mathrm{o}} / \mathrm{N}-\gamma\left(\mathrm{n}_{\mathrm{dd}, \mathrm{o}} / \mathrm{N}+\mathrm{n}_{\mathrm{w}, \mathrm{o}} / \mathrm{N}-\mathrm{n}_{\mathrm{d}, \mathrm{o}} / \mathrm{N}\right)}{\mathrm{n}_{\mathrm{w}, \mathrm{o}}\left(1-\lambda_{\mathrm{w}}\right) / \mathrm{N}+\mathrm{n}_{\mathrm{d}, \mathrm{o}} / \mathrm{N}}
$$

or by using the definitions of probability given by Eqs. 5a and $5 \mathrm{~b}$,

$$
\mathrm{P}_{\mathrm{n}}(\mathrm{d} / \mathrm{d})=1-\frac{\lambda_{\mathrm{W}} \mathrm{P}_{\mathrm{o}}(\mathrm{w})-\gamma\left[\mathrm{P}_{\mathrm{o}}(\mathrm{d}) \mathrm{P}_{\mathrm{o}}(\mathrm{d} / \mathrm{d})+\mathrm{P}_{\mathrm{o}}(\mathrm{w})-\mathrm{P}_{\mathrm{o}}(\mathrm{d})\right]}{\left(1-\lambda_{\mathrm{w}}\right) \mathrm{P}_{\mathrm{o}}(\mathrm{w})+\mathrm{P}_{\mathrm{o}}(\mathrm{d})}
$$

As our last step, we also need to compute the probability of a dry day from transitional probabilities. By using relationships of Eqs. $5 \mathrm{~b}$ and $6 \mathrm{a}$, the number of dry days is defined as

$$
\mathrm{n}_{\mathrm{d}}=\mathrm{n}_{\mathrm{w}} \mathrm{P}(\mathrm{d} / \mathrm{w})+\mathrm{n}_{\mathrm{d}} \mathrm{P}(\mathrm{d} / \mathrm{d})=\left(\mathrm{N}-\mathrm{n}_{\mathrm{d}}\right) \mathrm{P}(\mathrm{d} / \mathrm{w})+\mathrm{n}_{\mathrm{d}} \mathrm{P}(\mathrm{d} / \mathrm{d})
$$

or

$$
n_{d}=\frac{N P(d / w)}{1+P(d / w)-P(d / d)}
$$

We can then compute the probability of a dry day from existing transitional probabilities as

$$
\mathrm{P}_{\mathrm{o}}(\mathrm{d})=\frac{\mathrm{n}_{\mathrm{d}, \mathrm{o}}}{\mathrm{N}}=\frac{\mathrm{P}_{\mathrm{o}}(\mathrm{d} / \mathrm{w})}{1+\mathrm{P}_{\mathrm{o}}(\mathrm{d} / \mathrm{w})-\mathrm{P}_{\mathrm{o}}(\mathrm{d} / \mathrm{d})}
$$

and the probability of a wet day as

$$
\mathrm{P}_{\mathrm{O}}(\mathrm{w})=1-\mathrm{P}_{\mathrm{O}}(\mathrm{d})
$$

To summarize our proposed approach, the current transitional probabilities of $\mathrm{P}_{\mathrm{o}}(\mathrm{w} / \mathrm{w})$ and $\mathrm{P}_{\mathrm{o}}(\mathrm{w} / \mathrm{d})$ and current mean daily precipitation depth, $E\left(r_{o}\right)$ are known, and we can easily compute $P_{o}(d / d)=1$ $P_{o}(w / d)$ and $P_{o}(d / w)=1-P_{o}(w / w)$. The probabilities of $P_{o}(d)$ and $P_{o}(w)$ are computed from Eqs. 9. The user needs to select new climate change parameters of $f_{T}, f_{r}$ and $\gamma$. The ratio of the number of wet days can then be computed from Eq. 4a and the new daily mean precipitation depth using Eq. 3b. Finally, all of the parameters are now defined to compute the new transitional probabilities of $\mathrm{P}_{\mathrm{n}}(\mathrm{w} / \mathrm{w})$ and $\mathrm{P}_{\mathrm{n}}(\mathrm{d} / \mathrm{d})$ by Eqs. $7 \mathrm{a}$ and $7 \mathrm{~d}$, respectively.

An important step in the proposed approach is the selection of the value for $\gamma$. This parameter determines the change in the number of wet-wet days between the current and new climate conditions. Since wet-wet days are combinations that most likely result in hydrologic runoff events, the selection of $\gamma$ should be done thoughtfully. We will consider the implications of using $\gamma=1$ and $\gamma=\lambda_{w}$ in the next section.

\section{APPLICATION OF FRAMEWORK}

To illustrate the key features of the theoretical framework, the proposed method is applied to the stochastic parameters of daily precipitation determined by Green (1984) for the month of April. Green (1984) analyzed 80 years of daily precipitation from 1900 to 1979 for Stillwater, OK. For this period of record, the mean monthly precipitation depth for April was $84.3 \mathrm{~mm}$ and the mean daily precipitation depth for a wet day was $11.3 \mathrm{~mm}$. The number of wet, dry, wet-wet, dry-wet, wet-dry, and dry-dry days is given in Table 1. There are 2400 days for the month of April for an 80 -year record. The average number of wet days is 7.5 days for April.

By using the relative-frequency relationships of Eq. $5 \mathrm{~b}$, we can easily compute the transitional probabilities of $\mathrm{P}_{\mathrm{o}}(\mathrm{w} / \mathrm{w})=0.41$ and $\mathrm{P}_{\mathrm{o}}(\mathrm{w} / \mathrm{d})=0.20$. These probabilities are used to determine a wet or 
dry state in stochastic climate model using a first-order Markov chain (Richardson, 1981; Wilson et al., 2006). By using previously summarized relationships, we obtain $P_{o}(d / d)=0.80, P_{o}(d / w)=0.59, P_{o}(d)$ $=0.75$, and $\mathrm{P}_{\mathrm{o}}(\mathrm{w})=0.25$. The validity of these relationships can be verified using the relativefrequency equations of Eq. 5a.

Table 1. Summary of wet and dry state of precipitation for Stillwater, OK.

\begin{tabular}{|c|c|c|c|c|}
\hline \multirow{2}{*}{\multicolumn{2}{|c|}{ 然 }} & \multicolumn{2}{|c|}{ Next Day } & \multirow[b]{2}{*}{ Total } \\
\hline & & Dry & Wet & \\
\hline \multirow{3}{*}{$\begin{array}{c}\text { Current } \\
\text { Day }\end{array}$} & Dry & 1441 & 357 & 1798 \\
\hline & Wet & 357 & 245 & 602 \\
\hline & Total & 1798 & 602 & 2400 \\
\hline
\end{tabular}

The average number of wet days for the month of April under different climate change scenarios is easily computed using Eqs. $4 \mathrm{~b}$ and $4 \mathrm{a}$. This average is a function of the fractional changes in the total precipitation $\left(f_{T}\right)$ and mean daily precipitation depth $\left(f_{r}\right)$. The slope steepness increases with a decrease in $f_{r}$. The average number of wet days does not change under different climate conditions when $f_{r}=f_{T}$, that is, when the fractional change in total depth equals that of mean precipitation depth.

The role of the wet-wet-day parameter $\gamma$ on the change in transitional probabilities is shown in Figures 1 and 2. Change in the transitional probabilities of $P(w / w)$ and $P(d / d)$ are given as a function of the fractional change in the total precipitation depth for $\gamma=1$ and $\gamma=\lambda_{\mathrm{w}}$, where $\Delta$ symbol is used to indicate a difference between the new and current values. Also shown in these figures is the corresponding change in the number of wet-wet days. The fractional change in daily mean depth for these figures is one-half of the fractional change in the total precipitation depth, that is, $\mathrm{fr}=\mathrm{f}_{\mathrm{T}} / 2$.

Let's first consider the implication of selecting $\gamma=1$. For this parameter value, the number of wet-wet days is constant from Eq. 6e. If the total number of wet days increases $\left(f_{T}>0\right)$, then the transitional probability of $\mathrm{P}_{\mathrm{n}}(\mathrm{w} / \mathrm{w})$ must correspondingly decrease to maintain the same number of wet-wet days. This corresponds to the negative $\Delta \mathrm{P}(\mathrm{w} / \mathrm{w})$ and $\Delta \mathrm{P}(\mathrm{d} / \mathrm{d})$ for $\mathrm{f}_{\mathrm{T}}>0$. There is then less dependence on the next day staying wet if the current state is wet and less dependence on the next day staying dry if the current state is dry. New storms develop more often on dry days and dissipate more rapidly on wet days. If, on the other hand, $\mathrm{f}_{\mathrm{T}}<0$ with a corresponding decrease in the number of wet days, then $\Delta \mathrm{P}(\mathrm{w} / \mathrm{w})>0$ and $\Delta \mathrm{P}(\mathrm{d} / \mathrm{d})>0$. Storm patterns tend to dissipate more slowly resulting, on average, in more frequent consecutive days with precipitation that is reflected in a larger transitional probability of wet-wet days. Since the total number of wet days is decreasing, there are more consecutive days of no precipitation corresponding to a larger transitional probability of dry-dry days.

Change in transitional probabilities and number of wet-wet days for $\gamma=\lambda_{w}$ is shown in Fig. 2 . From Eq. 7a, this value results in no change in the transitional probability of $\mathrm{P}_{\mathrm{n}}(\mathrm{w} / \mathrm{w})$. This suggests the persistence of a given storm system does not change with new climate conditions. If the number of wet days increases (for $\mathrm{f}_{\mathrm{T}}>0$ ), then the number of wet-wet days increases because there are simply more storms. The total number of dry days must decrease for an increase in number of wet days. Since the transitional probability of $\mathrm{P}_{\mathrm{n}}(\mathrm{d} / \mathrm{w})$ also doesn't change for climate conditions, the reduction in the $P_{n}(d)$ is then obtained by a decrease in $P_{n}(d / d)$. Likewise, if the number of wet days decreases (for $\left.\mathrm{f}_{\mathrm{T}}<0\right)$, then there is a decrease in the number of wet-wet days because of fewer storms. There is a corresponding increase in the number of dry days as a consequence of an increase in $P_{n}(d / d)$. 


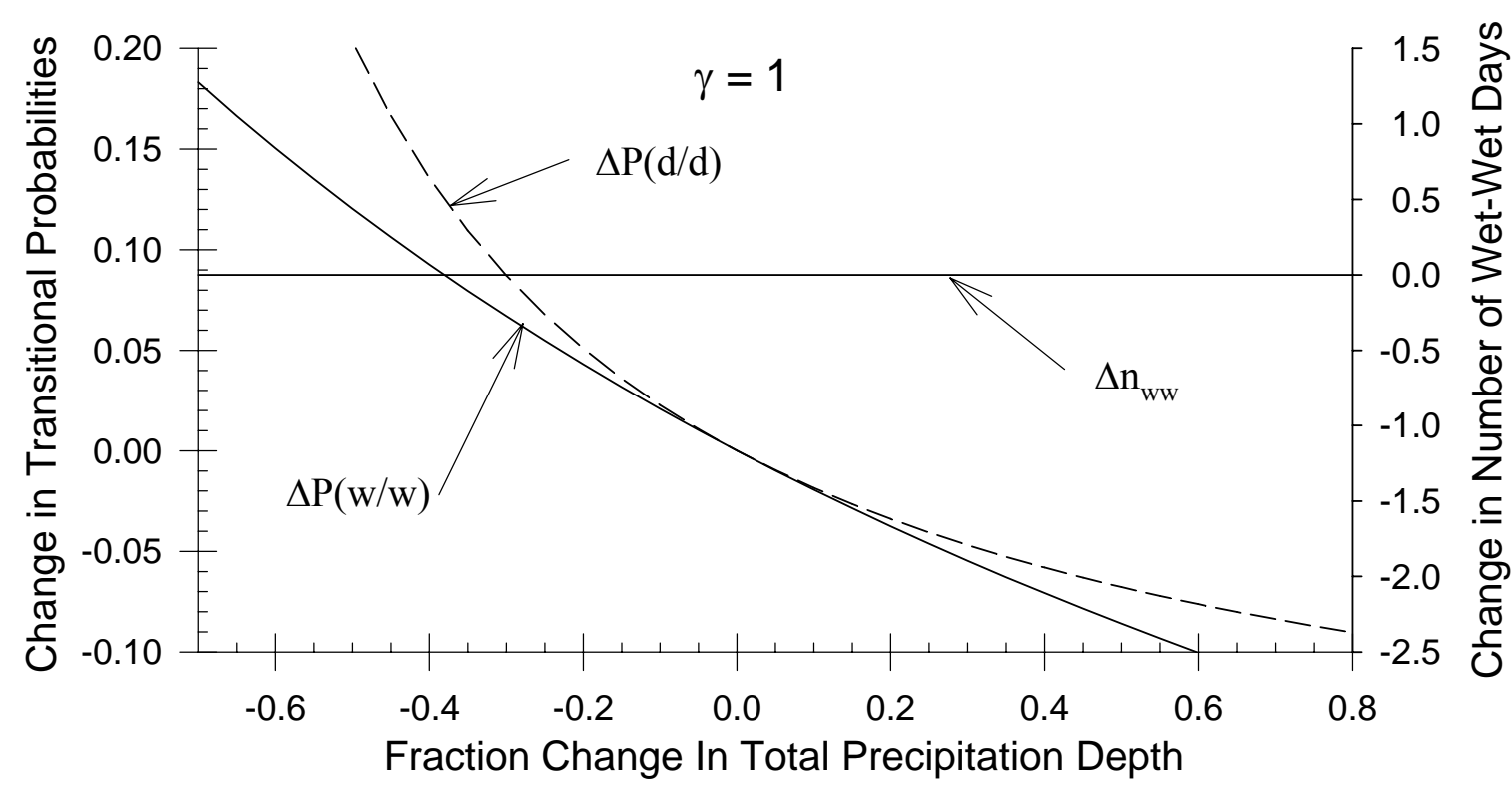

Figure 1. Change in transitional probabilities and number of wet-wet days for $\gamma=1$.

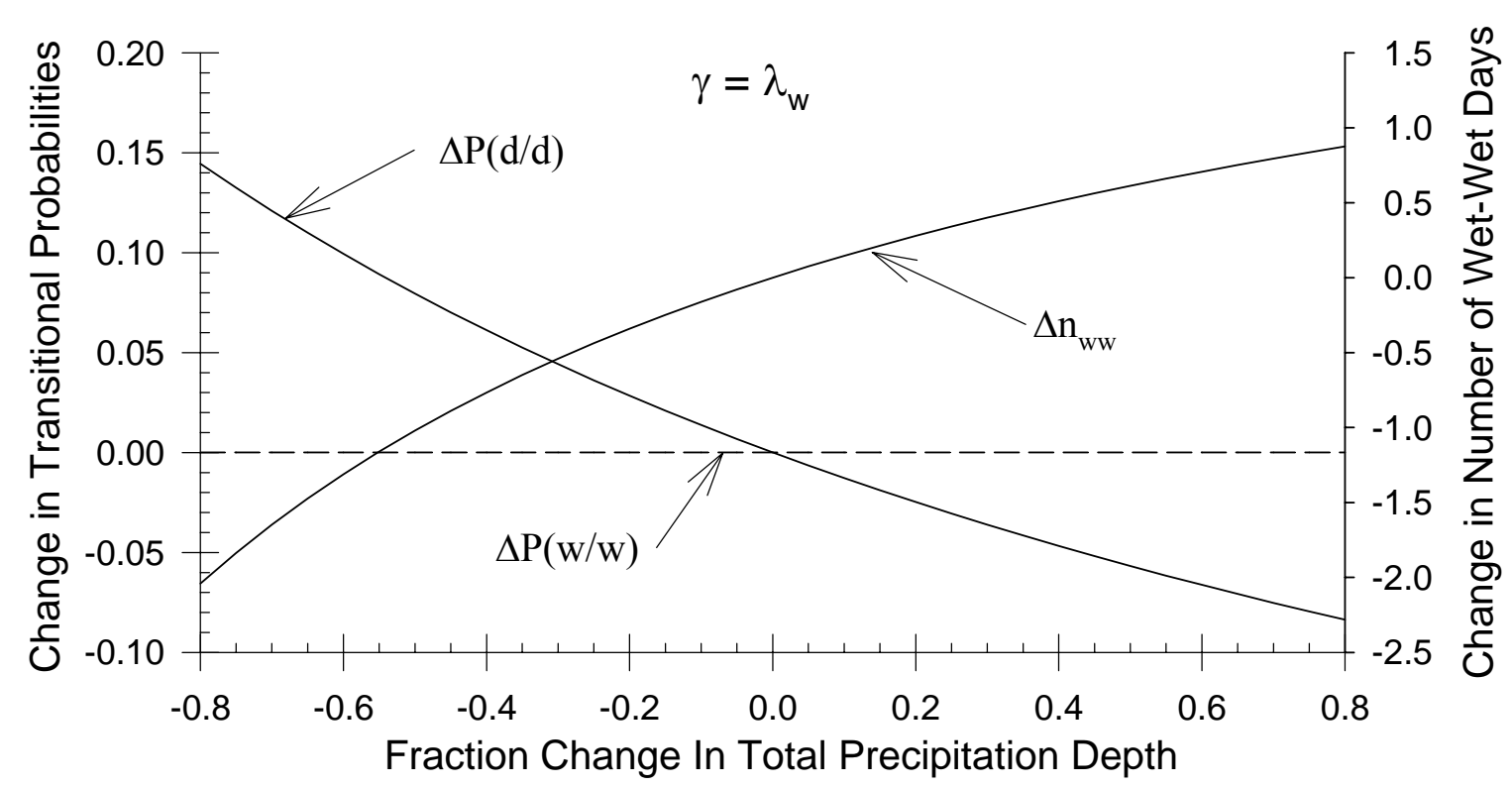

Figure 2. Change in transitional probabilities and number of wet-wet days for $\gamma=\lambda_{w}$.

\section{CONCLUSION}

Erosion processes are influenced by changes in climate. Powerful tools to simulate the impact of climate change on erosion are stochastic climate models. These models need to adjust the ensemble statistical parameters obtained under current conditions to those corresponding to climate change. For daily non-precipitation climate data, the conversion of the statistics is relatively easy using either a multiplicative or additive random variable. However, the consideration of a change in total precipitation depth is more complex because the new depth can be obtained by changing the daily mean precipitation depth, the number of wet days, or both. 
An approach was derived to allow for changes in total precipitation depth under different climate conditions. The computation of the new number of wet days is easily computed from input information on the fractional change in total precipitation depth and daily mean precipitation. Relationships were developed to compute the new number of wet days from current transitional probabilities of wet-given-wet days and wet-given-dry days. These relationships require the specification of an input parameter for the change in the number of wet-wet days. The implication of selecting two values of this parameter was evaluated using statistics reported for Stillwater, OK. The parameter value was found to be related to the persistence of storm systems.

\section{REFERENCES}

1. Green, J.E.P. 1984. Synthetic rainfall and its use in hydrologic modeling. Unpublished PhD diss. Stillwater, Okla.: Graduate School, Oklahoma State University.

2. Haan, C.T. 2004. Statistical Methods in Hydrology. Ames, Iowa: Iowa State University Press.

3. Nicks, A.D., L.J. Lane, and G.A. Gander. 1995. Chapter 2. Weather Generator. In USDA-Water Erosion Prediction Project hillslope profile and watershed model documentation. NSERL Report No. 10. D.C. Flanagan and M.A. Nearing, eds. West Lafayette, Ind.: USDA-Agricultural Research Service National Soil Erosion Research Laboratory

4. Richardson, C.W. 1981. Stochastic simulation of daily precipitation, temperature, and solar radiation. Wat. Resour. Res. 17(1): 182-190.

5. Wilson, B.N., A.Y. Sheshukov. and R. Pulley. 2006. Erosion Risk Assessment Tool for Construction Sites. Minnesota Department of Transportation, Research Report No. MN/RC-200627.

6. Wilson, B.N., and A.Y. Sheshukov. 2006. A process based erosion and sediment model for construction sites. In Proc. World Environmental and Water Resources Congress. Omaha, Nebr.: ASCE. 